\title{
Determination of stresses in tooth roots of gears by Integral Strain Gauges
}

\author{
Vladimir Syzrantsev \\ D. Sc. Eng, Professor \\ Tyumen Industrial University \\ Tyumen, Russia \\ syzrantsevvn@tyuiu.ru
}

\author{
Ksenia Syzrantseva \\ $\mathrm{PhD}$, Associate Professor \\ Tyumen Industrial University \\ Tyumen, Russia \\ kv.syzr@gmail.com
}

\begin{abstract}
Information about value and distribution law of stresses along tooth root of gears allows one to estimate loading capacity and durability of gear transmissions in real operation conditions. The paper considers new original means for determination of stresses in tooth roots - Integral Strain Gauges. Results of stress determination in roots of straight teeth of satellites of planetary gears are presented. Authors have established that use of satellites with longitudinal modification of teeth allows reducing the stress concentration by $20 \%$. The sensitivity of gearings to relative location errors of gears in accordance with the value and stress distribution law in tooth roots was researched during stand operations of NovikoffWildhaber's gearing with two contact lines and cylindrical gearings with arch-shaped teeth with use of Integral Strain Gauges. The possibility of experimental research of loading capacity of gear transmissions in operational conditions with the gauges is shown by the example of estimation of stress distribution in tooth roots of sun pinion of a planetary reducer of the tractor.
\end{abstract}

Keywords-durability, stress distribution, operational conditions, gearing, Integral Strain Gauges, cyclic deforming

\section{INTRODUCTION}

A variety of the constructive forms and performances of modern machine's transmissions, complexity of random factors influence, considered during estimation of carrying capacity, compliance and mutual location of details lead to situation when the data about conditions of gears functioning in structure of machine unit, used during gearing designing, can essentially differ from real ones. In this connection, the information about gearing carrying capacity, obtained during stand or operational tests of machines, takes on paramount significance.

This paper considers opportunities of design-technological completion of various types of gearings with the help of Integral Strain Gauges (ISG) - original means of registration of cyclic strains, arising on the detail surface at their cyclic loading [1-5].

\section{INTEGRAL STRAIN GAUGES CHARACTERISTICS}

Integral Strain Gauges of a required configuration are made of a metal foil (copper, aluminum, nickel and others [6, $7,8,9,10,11]$.), obtained by galvanic precipitation and subjected to special thermal processing and machining. The size of an initial sheet for ISG manufacturing is $50 \times 50 \mathrm{~mm}$, thickness of foil is $10 \ldots 30$ microns. Depending on gauge material, electrolyte components, electrolysis and thermo mechanical machining parameters and foil thickness, the sensitivity of gauges on loading cycles' number before appearance of their reaction at given amplitude of cyclic strains varies from several thousands up to several millions cycles. As a result of cyclic strains' influence, the structure of gauge material changes and reaction appears on its surface as "dark spots". The moment of appearance of first "dark spots" and the first grain of the changed structure of gauge material, as well as their density and sizes correlate with the number of loading cycles and cyclic strains amplitude. Besides, other ways of estimation of ISG reaction are developed [1]: by the size of the relative area of the changed structure, by the change of micro hardness, by the change of reflected from gauge surface light flow or infrared radiation $[1,2,4,5]$.

In contrast to strain gauges [12, 13], ISG have not electric wires and any switches. Properties of metal foil are identical in all directions, therefore ISG do not need to be oriented on detail surface. They have not base of measurement. An error of cyclic stress estimation with the help of ISG is no more than 5\% [1], at that achieved locality of measurement - on site of surface about $0,1 \mathrm{~mm}$. Gauges allow establishing places of stress concentration on details surfaces in real conditions of their work at temperature up to $100^{\circ} \mathrm{C}$ (limiting temperature of used glue).

As a result of complex of experimental and theoretical researches $[1,2]$ authors established that in a range of cyclic stress amplitude change, which takes place at resource tests of details, ISG react at the same value of detail material damage. It allows one to establish places of probable destruction of details and to obtain data for development of methods of resource forecasting of machine parts and units after short endurance tests with ISG

\section{EXPERIMENTAL RESEARCH OF GEARINGS WITH USE OF INTEGRAL STRAIN GAUGES}

The law of stress $(\sigma)$ or strain $(\gamma)$ distribution in the tooth root is the integrated characteristic of gearing serviceability. This law contains information which allows one to estimate influence of contact localization, geometrical parameters of 
gears, norms of accuracy on carrying capacity of gears because it is necessary during design and technological completion of gearings.

The solution of practical tasks using the ISG is carried out in two stages. At the first stage, the construction of calibrating dependences (usually on special specimens) [1] for ISG comes true. At the second stage, obtaining the information on ISG, placed on researched places of detail surface, is carried out. Both stages are realized in conditions of cyclic loading of specimens or detail.

Change of surface condition or ISG properties, accepted as their reaction to cyclic strains value, is displayed in the various forms and depends on loading conditions of details. In this connection, the calibrating of ISG, ensuring an opportunity of measurement, is carried out by various methods: by first "dark spots" and first grains of the changed structure, by change of micro hardness and others $[1,2]$. Depending on the accepted criterion of ISG reaction estimation, the sequence and types of operations vary during method realization. The choice of the method is defined by access to ISG for obtaining the information, opportunity of repeated stops of tests of the researched transmission unit for ISG removal and other conditions $[1,2]$.

It is necessary to consider the basic stages of method [1] of stress change determination with the help of ISG, fixed in the tooth root. The gauges' reaction is estimated by the surface effect (first "dark spots"). Before experimental researches, ISG are calibrated. The purpose of calibration is determining the calibrating dependence which connects the number of loading cycles $\mathrm{N}$ and stress amplitude $\mathrm{s}$ in accordance with criteria of ISG reaction as first "dark spots". Integral Strain Gauge is a strip of a galvanic foil, placed (pasted) on the conic working part of a cylindrical specimen (Fig.1). The traditional scheme of gauge calibration is presented in Fig. 2. The specimens are subjected to cyclic deforming on a fatigue testing machine [14] in conditions of bend with rotation or in conditions of pure bending (Fig.3).

Application of samples with a conic working part allows determining the ISG reaction in some range of stress (strain) variation during gauge calibration because the same load applies different stresses in all sections of a conic working part of specimen (Fig. 1).

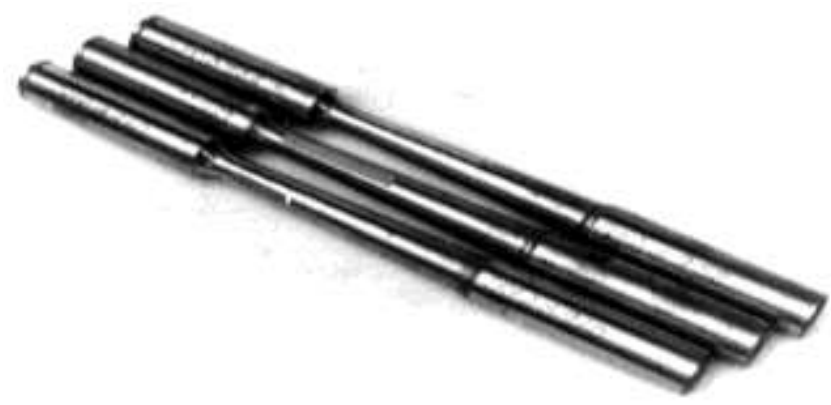

Fig. 1. Cylindrical specimens for ISG calibration
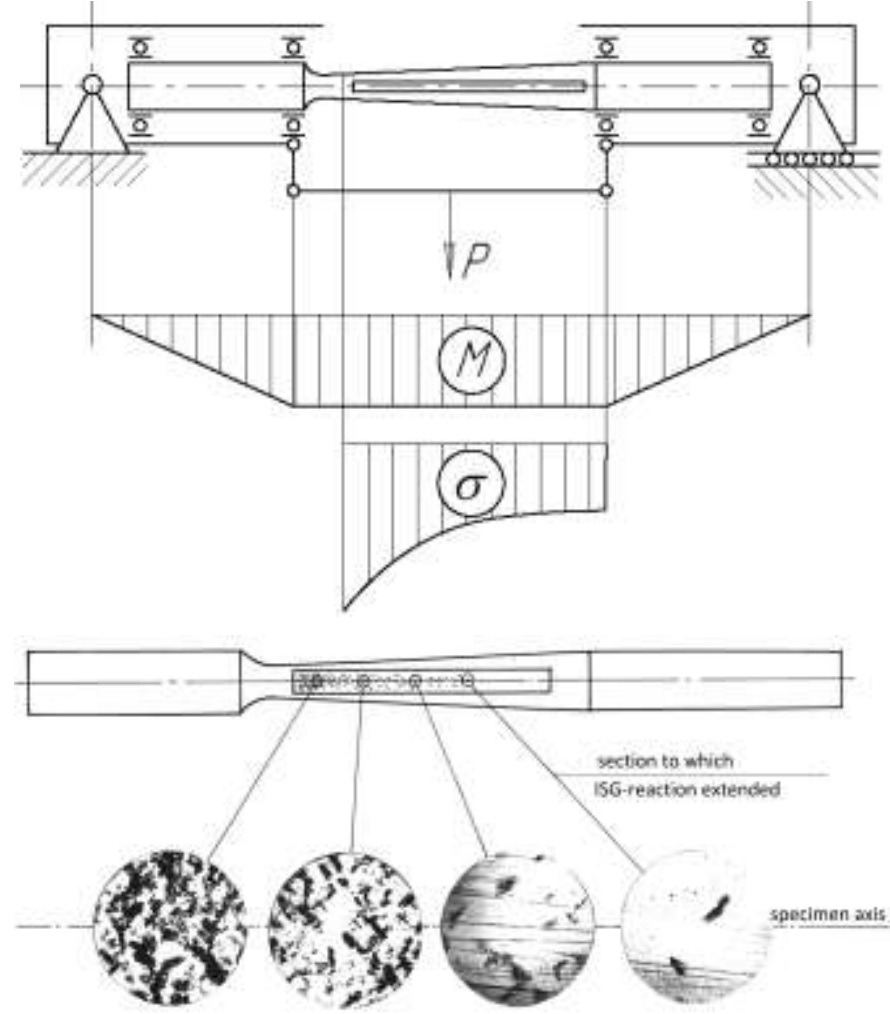

Fig. 2. Calibration of Integral Strain Gauges during cyclic deforming of specimen on fatigue testing machine

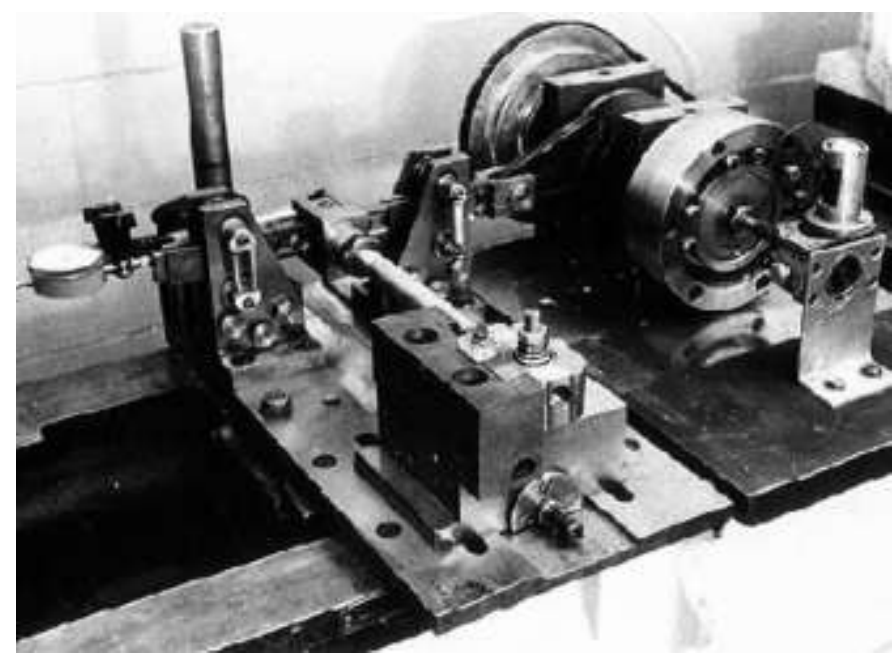

Fig. 3. Fatigue testing machine for ISG calibration

With the known scheme of specimen's loading and bending moment $M$, stress $\sigma$ and strain $\gamma$ are calculated according to formulas:

$$
\sigma_{i}=\frac{32 \cdot M}{\pi \cdot d_{i}^{3}}, \gamma_{i}=\frac{16 \cdot M}{\pi \cdot d_{i} \cdot G}
$$

where $d_{i}$ - diameter of specimen in $i$-th section of the working part, $G$ - shear modulus of specimen material. 
During gauge calibration, first "dark spots" appear in the specimen section with the minimum diameter. At increase in number of loading cycles of specimen first "dark spots" move in direction of the bigger diameter of conic working part of specimen. As a result of calibration, $n$ couples of $\sigma_{i}$ and $N_{i}$ values, defining experimental points of calibration dependence, are obtained.

The example of calibrating dependence for the aluminum gauge and material of the studied gears is shown in Fig. 4. Its mathematical description looks like:

$$
N=0,379 \cdot 10^{9}\left(\frac{1}{\sigma-3,49}-\frac{1}{1,01 \cdot \sigma}\right) .
$$

The idea of this method consists in registration of kinetic processes of ISG surface effect borders (coordinate $X_{i}$ ) moving in a longitudinal direction of the tooth in accordance with increase of the number of loading cycles $N_{i}$. Values $X_{i}$ and $N_{i}$, taking into account calibrating dependence $\sigma=\sigma(N)$ (it is constructed by the criterion of appearance of first "dark spots" on ISG, placed on the conic part of round specimens, subjected to test in conditions of bend with rotation), define set $\sigma_{i}$ in various $(i$-th) tooth front sections, which correspond to coordinate $X_{i}$. This set is the law of stress change in a longitudinal direction of the tooth.

\section{Stress $\sigma, \mathrm{MPa}$}

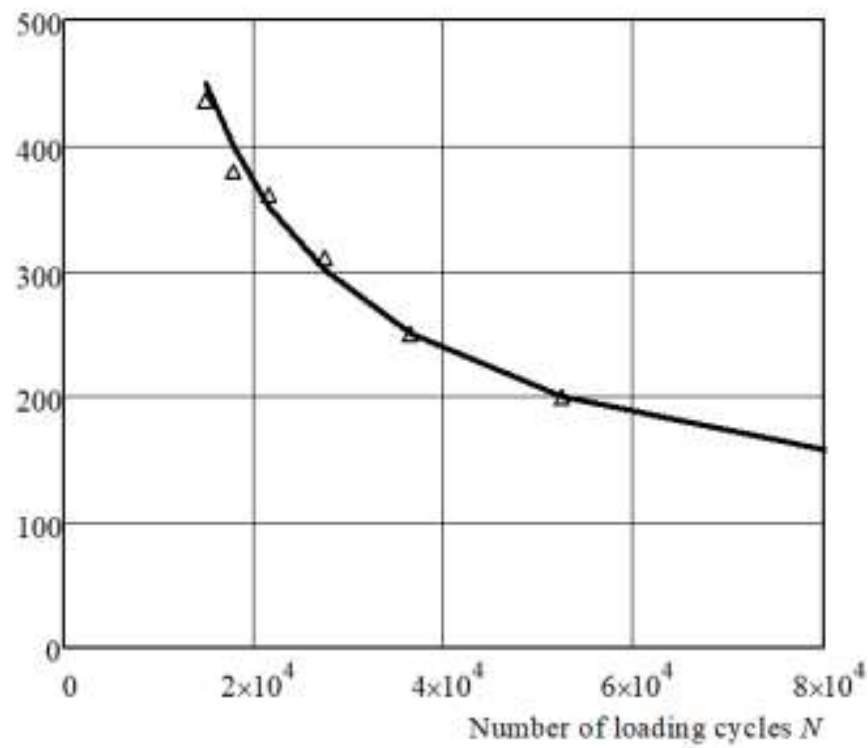

Fig. 4. Calibrating dependence for Integral Strain Gauges

\section{EXAMPLES OF APPLICATION OF INTEGRAL STRAIN GAUGES FOR LOADING CAPACITY ESTIMATION OF DIFFERENT GEARINGS}

Let us present some results of using method [1]. Fig. 5 shows strain change in the tooth root, and Fig. 6 - in the barrel-shaped tooth of satellites $\left(Z=23, b_{w}=40 \mathrm{~mm}, m=5 \mathrm{~mm}\right)$ of the planetary mechanism of the gear box of tractor T-330.

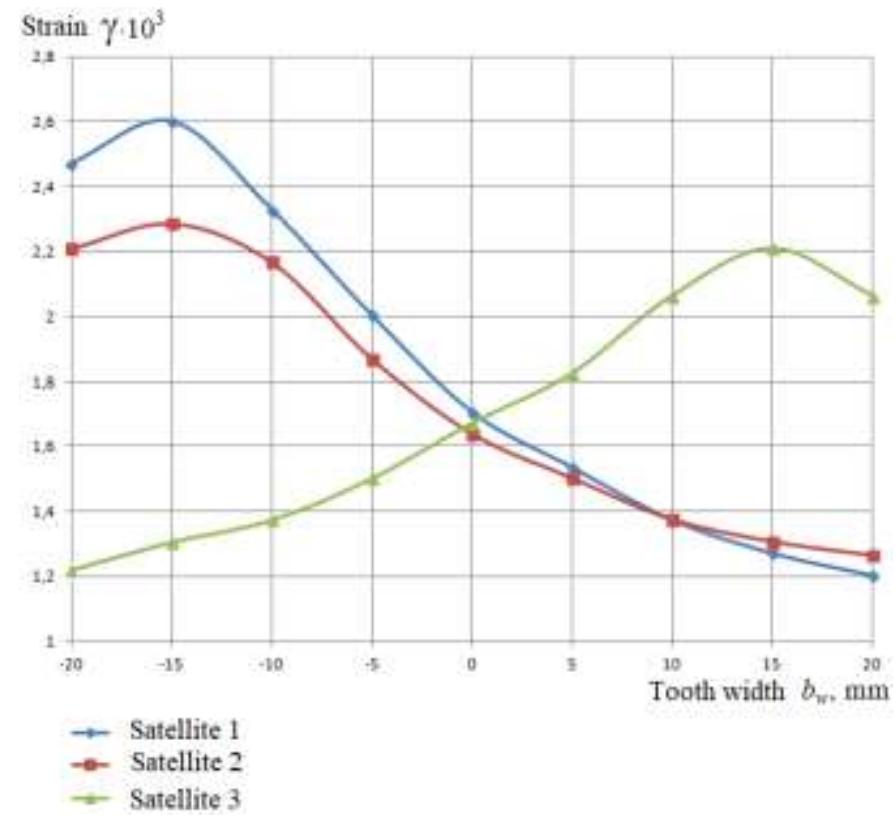

Fig. 5. Strain change in straight tooth root of satellites

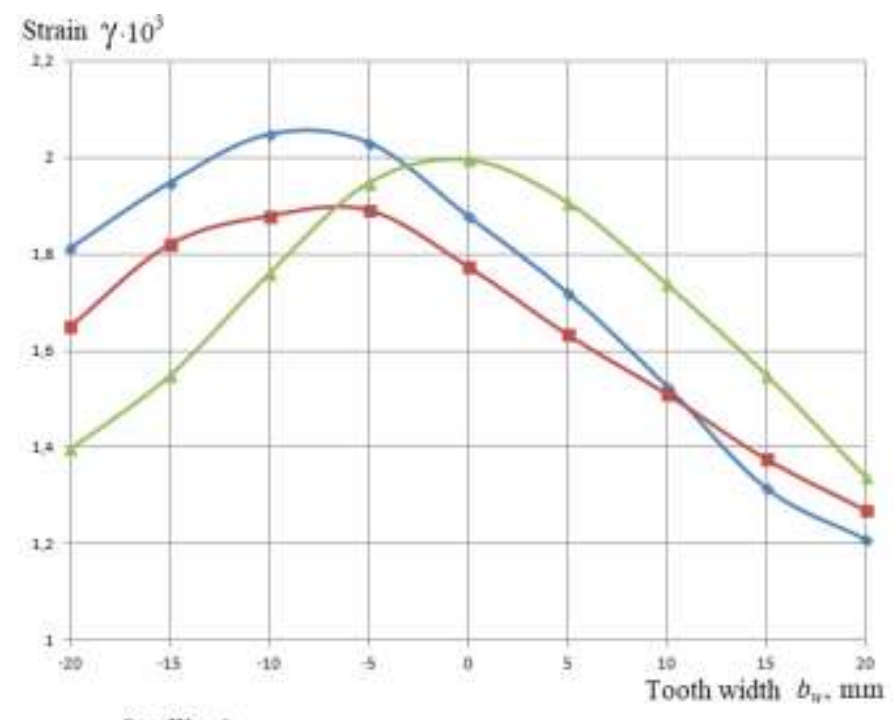

$\rightarrow$ Satellite 1

- Satellite 2

- Satellite 3

Fig. 6. Strain change in barrel-shaped tooth root of satellites

The stress concentration factor values $\left(K_{F \beta}\right)$, calculated in accordance with method [1] for satellites in Fig.5, are: $K_{F \beta}^{1}=1.43 ; K_{F \beta}^{2}=1.29 ; K_{F \beta}^{3}=1.31$, and for satellites in Fig.6 $K_{F \beta}^{1}=1.18 ; K_{F \beta}^{2}=1.13 ; K_{F \beta}^{3}=1.16$.

According to Fig. 5, the signs of a skew angle of satellites are different. The reason of the described situation was an unsuccessful combination of errors of manufacturing and assembly of researched unit parts. Comparing Fig.5 and Fig.6, let us establish that introduction of longitudinal localization of contact $(\Delta=0.03 \mathrm{~mm})$ leads to a reduction $(\approx 20 \%)$ of the maximum value of strains (stresses) in the tooth root. 
Fig.7 illustrates the solution of the influence estimation task of manufacture errors of gears with Novikoff-Wildhaber's meshing [15] on the local bend stress value.

Four gears of the low-speed stage of the two-stage reducer were tested during their rolling on the stand under load. The low-speed stage of the reducer $(m=6.3 \mathrm{~mm})$ is NovikoffWildhaber's gearing with two contact lines. Two parameters common normal length deviation and base pitch deviation were varied during realization of the experiment.

The analysis of Fig.7 shows that common normal length deviation of the relatively standard gear (curve 1 has errors of controlled parameters in permissible limit) to the positive area (+50microns, curve 2$)$ and to the negative area ( -155 microns, curve 3) in comparison with the normalized tolerance area leads to growth of the maximum stresses in tooth roots by $16 \%$ and $13 \%$.

And base pitch deviation (+143microns, curve 4$)$ leads to an increase of the maximum stresses in tooth roots by $12 \%$. It is necessary also to note essentially other character of stress distribution in tooth of Novikoff-Wildhaber's gears in comparison with involutes ones (Fig.5, Fig.6).

Fig. 8 shows the planetary reducer of the four-axle tractor and Fig. 9 - sun pinion $(Z=16, m=5 \mathrm{~mm})$ with placed Integral Strain Gauges.

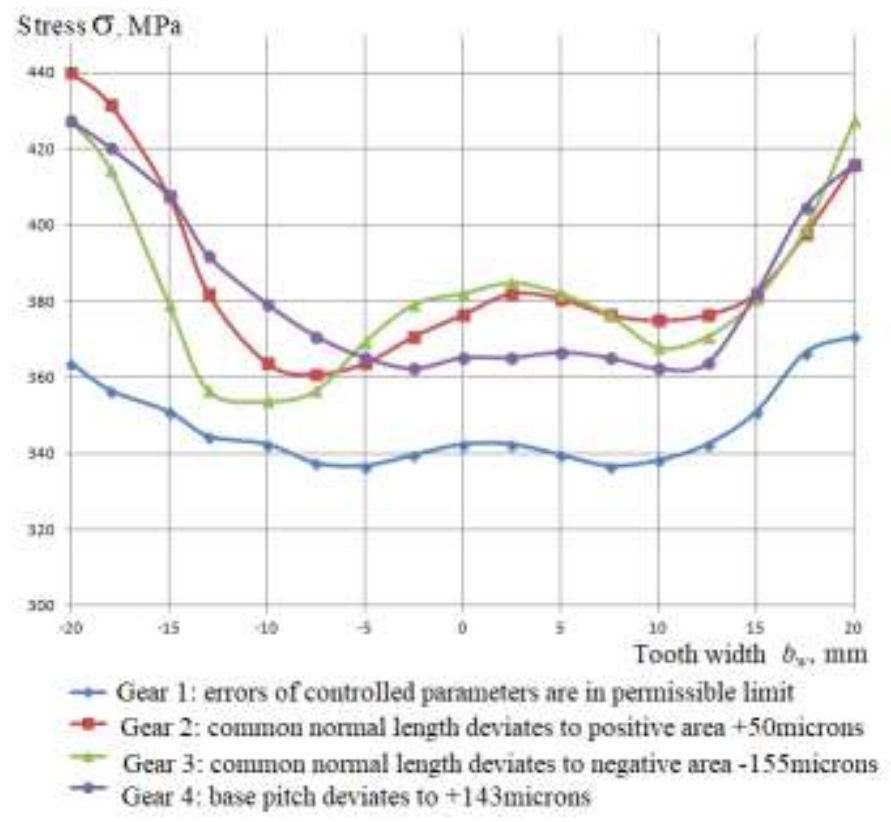

Fig. 7. Strain change in straight tooth root of satellites

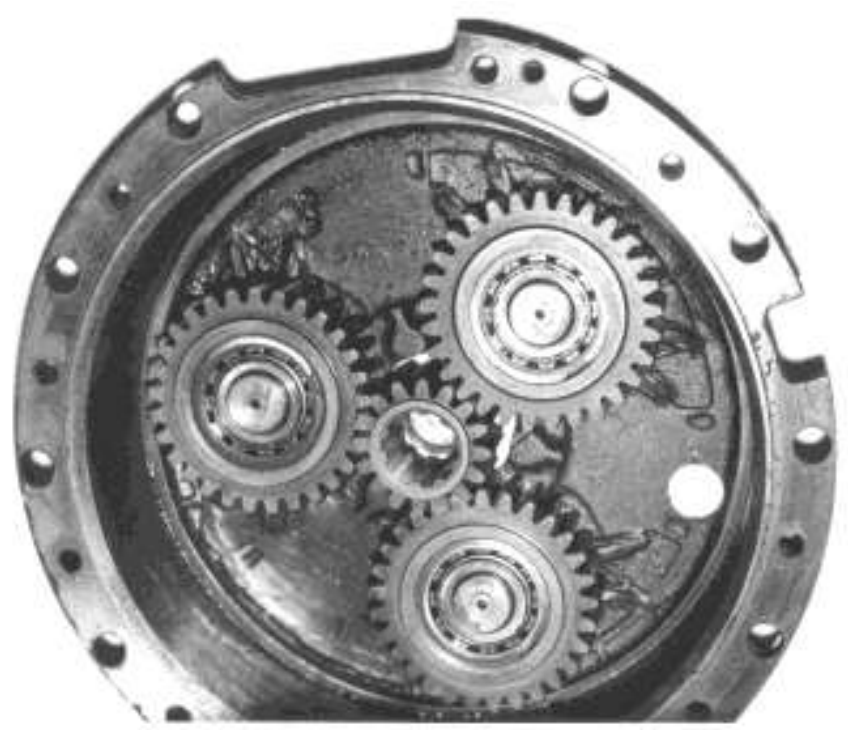

Fig. 8. Planetary reducer of four-axle tractor

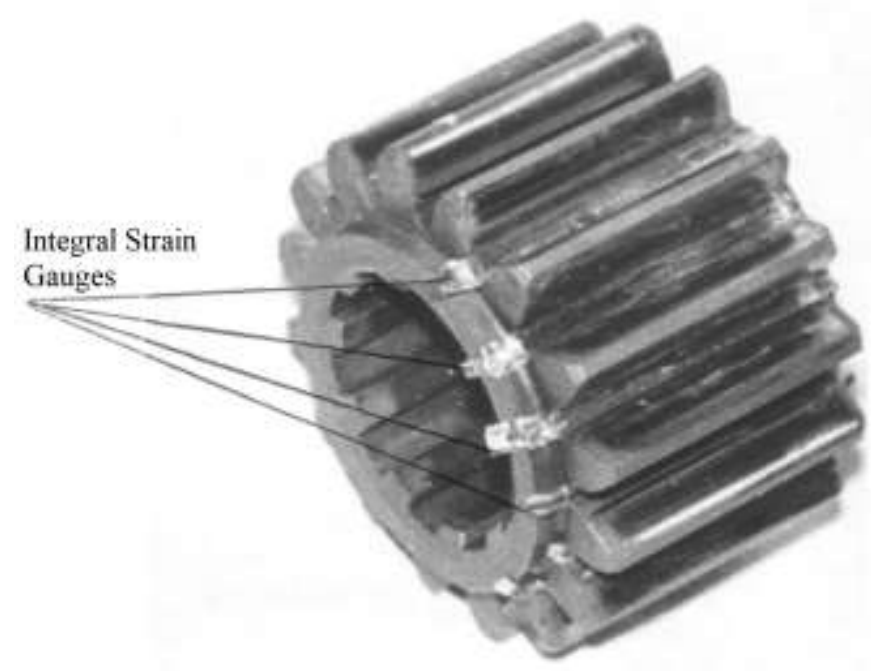

Fig. 9. Sun pinion with Integral Strain Gauges

Stress distribution in the straight tooth root of the sun pinion of serial and pilot reducers of the tractor is presented in Fig.10 and Fig.11.

The registration of indications of ISG, pasted in tooth roots, came true after $53,95,137,189,142,349,1135 \mathrm{~km}$ of the race track of the tractor. Four rear board reducers of eight were researched, as the most loaded. Two reducers had a planet carrier of the experimental construction, two - of serial construction. The serial construction of the planet carrier had two-support mounting of satellite axes, and the experimental construction had console mounting. Experimental data obtained with the help of ISG have shown that in the experimental construction, the stress concentration in sun pinion tooth roots does not grow. Calculated values of factors $K_{F \beta}$ also confirm it: for experimental variants they are 1.06 and 1.11 , and for serial -1.09 and 1.13 . 


\section{Stress $\sigma, \mathrm{MPa}$}

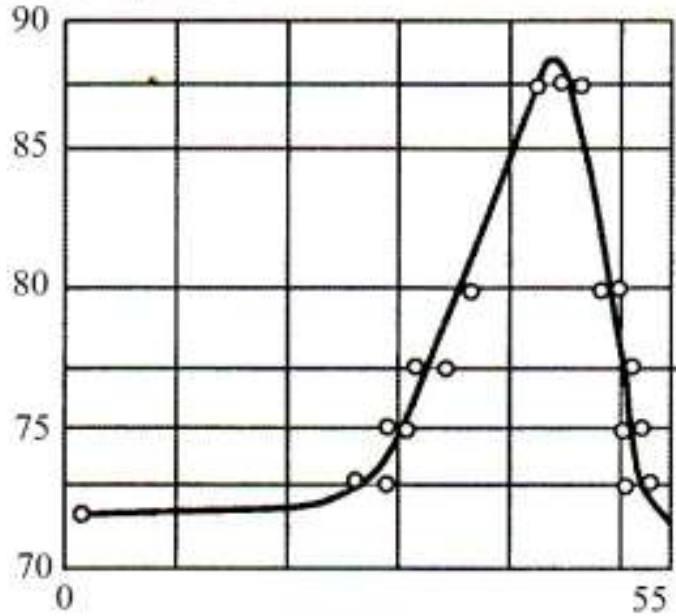

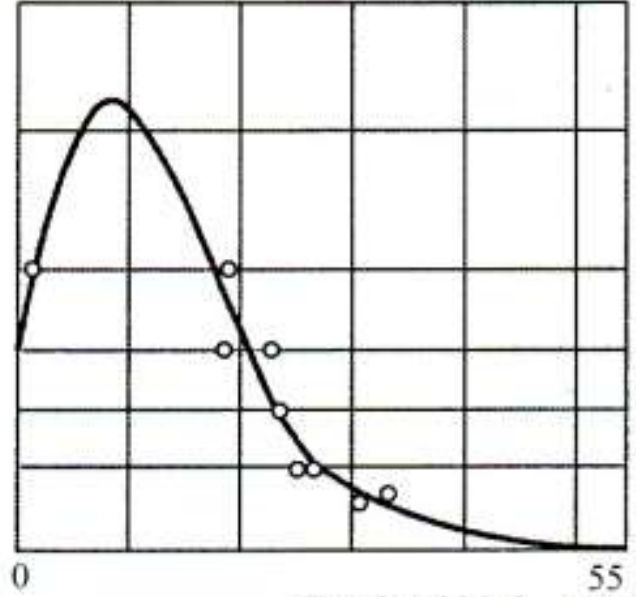

Tooth width $b_{w}, \mathrm{~mm}$

Fig. 10. Reducers of third axe of tractor ( $\mathrm{a}-$ right serial, $\mathrm{b}$ - left pilot)

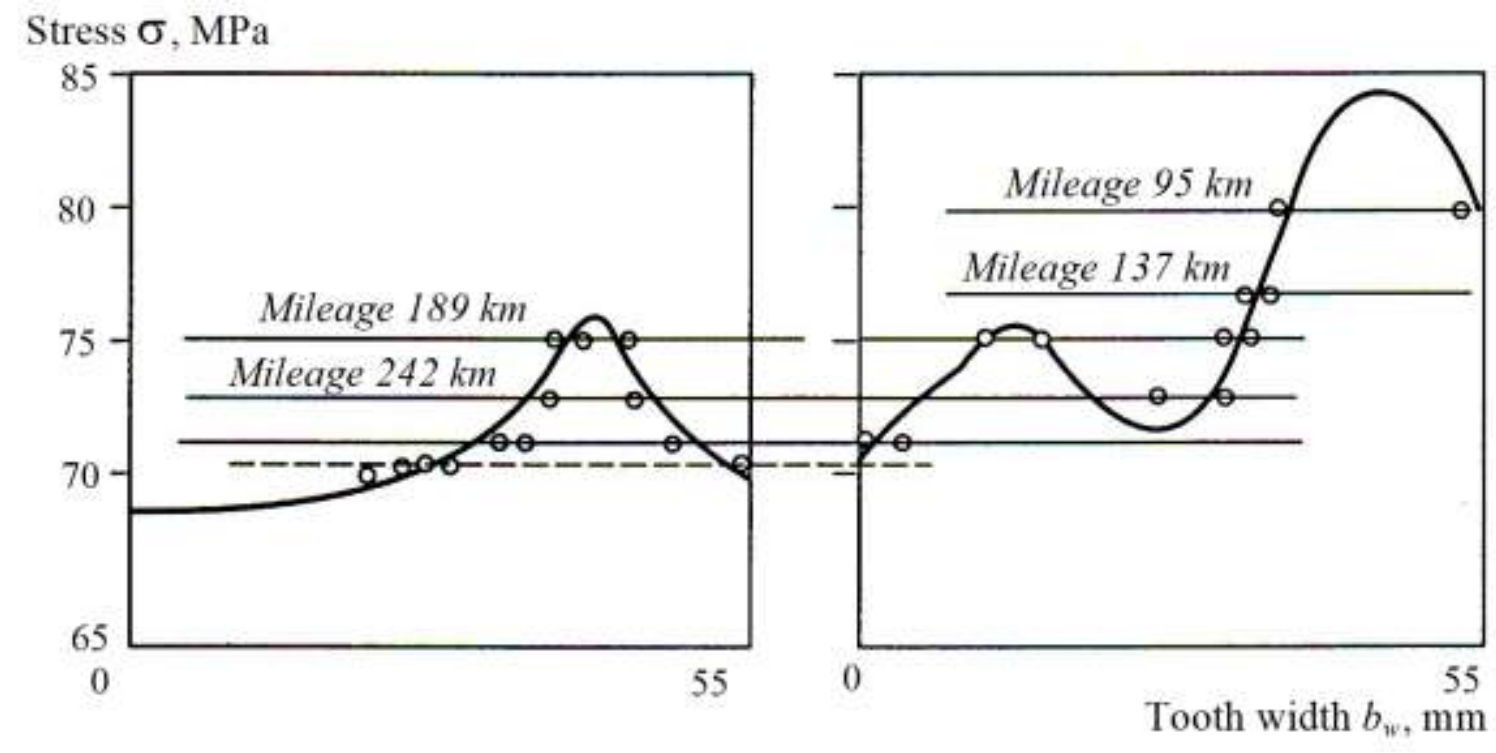

Fig. 11. Reducers of fourth axe of tractor ( $\mathrm{a}$ - right pilot, $\mathrm{b}-$ left serial)

Fig. 12 and Fig.13 show the results of the research of stress distribution in arch-shaped tooth roots of cylindrical gears at various skew angles of gear axes: $0 ; 3$ '; 6'; 9'. Parameters of gearing were: $Z_{1}=13, Z_{2}=47, m=5 \mathrm{~mm}$, the calculation radius of the tool cutting part is $100 \mathrm{~mm}$. Fig. 12 shows stress change on the pinion tooth length for a case of localized contact in meshing. The data of Fig.13 correspond to gearing with archshaped teeth. In each phase of its functioning, the contact of pinion and wheel surfaces takes place in two distributed along tooth length zones. This gearing is adaptive both to external load and to field of errors of mutual location.

\section{CONCLUSION}

The considered examples of gearing loading capacity determination testify that developed means of experimental research - Integral Strain Gauges and methods of their use have wide universality and large potential opportunities. Expanding an arsenal of measurement means, ISG are especially effective during creation of systems of serviceability and fatigue diagnostics of gears in real conditions of machines functioning. 


\section{Stress $\sigma \cdot \mathrm{MPa}$}

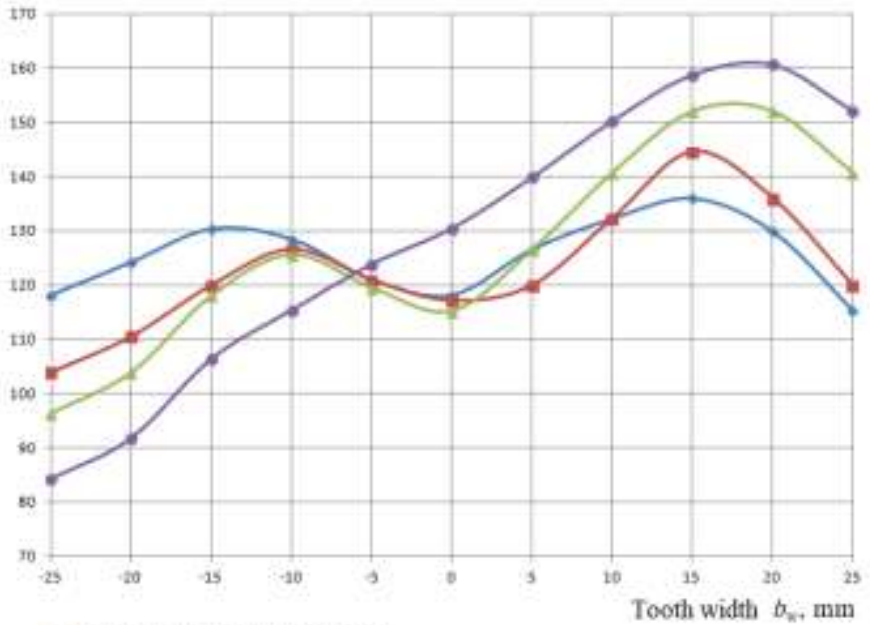

+ Skew angle of gear axes is 0

- Skew angle of gear axes is $3^{\prime}$

- Skew angle of gear axes is $6^{\prime}$

- Skew angle of gear axes is 9 .

Fig. 12. Stress change on pinion tooth length in localized contact in meshing

\section{Stress $\sigma, \mathrm{MPa}$}

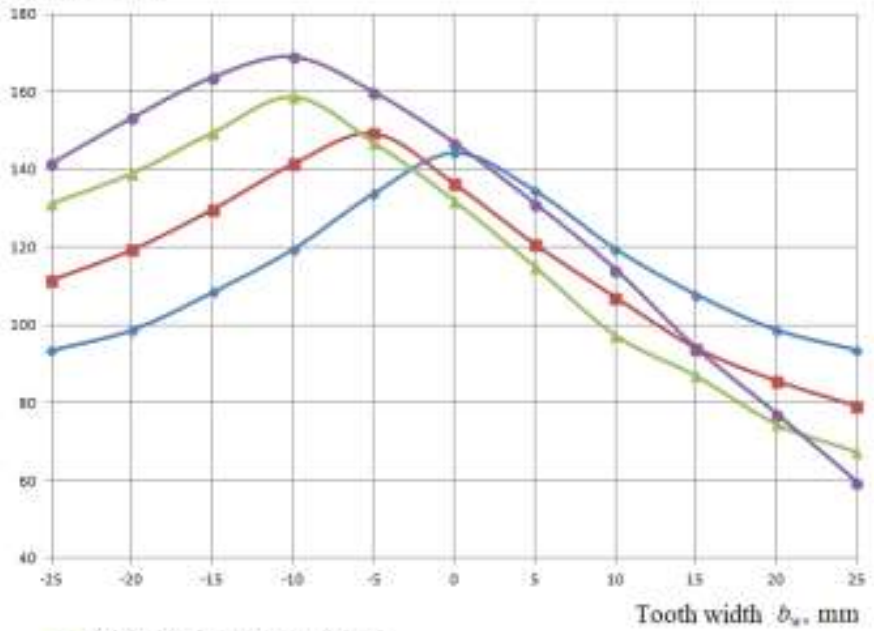

- Skew angle of gear axes is 0

- Skew angle of gear axes is $3^{\prime}$

- Skew angle of gear axes is $6^{\prime}$

$\rightarrow$ Skew angle of gear axes is $9^{\prime}$

Fig. 13. Stress change in arch-shaped tooth roots

\section{References}

[1] V.N. Syzrantsev, S.L. Golofast, Cyclic strain measurement and machine parts longevity forecasting according to integral strain gauges indications, Novosibirsk, Nauka, 2004.

[2] V. Syzrantsev, K. Syzrantseva, "The stress-strain condition estimation of detail in crack tip by integral strain gauges," IOP Conf. Series: Mat. Sc. and Eng, Vol. 127, 012051, 2016.

[3] S.V. Panin, A.V. Eremin, P.S. Lyubutin, M.V. Burkov, "Investigation of various criteria for evaluation of aluminum thin foil "smart sensors" images," IOP Conf. Series: Mat. Sc. and Eng, Vol. 66, 012024, 2014.

[4] M. Burkov, S. Panin, P. Lyubutin, A. Eremin, "An approach for structural health monitoring of CFRP using aluminum foil sensors," 11th Europ. Conf. on Non-Destructive Testing (ECNDT 2014- Prague), 2014, 16703.

[5] M. Burkov, S. Panin, P. Lyubutin, A. Eremin, P. Maruschak, A. Menou, "Aluminum foil based fatigue sensor for structural health monitoring of carbon fiber composites," Procedia Technology, Vol. 19, pp. 307-312, 2015.

[6] M. Seika et al, "Examination of the Adaptability of the Copper Electroplating Method of Stress Analysis to the Low Temperature Range,” Bulletin of the JSME, Vol. 17, №107, 1974.

[7] M. Seika, S. Kitaoka, "A Study on the Improvement in Sensitivity of Strain Gauges Made of Copper Electrodeposited Foil," Bulletin of the JSME, V. 27, No.234, pp. 2664-2669, 1984.

[8] Ono Y., Kitaoka S. Cyclic stress measurement method using grain size and occurrence rate of grown grains in electrodeposited copper foil Strain, Vol. 47, Iss.2, pp. 154-161, 2011.

[9] Y. Ono, S. Morito, "Effect of ambient temperature on stress measurement method using copper foil," Strain, Vol. 50, Iss.4, pp. 292 300, 2014.

[10] Y. Nagase, Y. Sawaki, F. Moritake, H. Yoshida, "Fatigue gage utilizing surface roughening of aluminum foil," J. Eng.Mater.Tech, Vol. 117, pp. 55-61, 1995.

[11] Nagase Yasuo, Nakamura Yoshiyuki, "Fatigue gauge utilizing slip deformation of aluminum foil," JSME Int. J., Series 1, Vol. 35, pp. 247 252, 1992.

[12] Ni Y-Q, Xia Y-X, "Strain-Based Condition Assessment of a Suspension Bridge Instrumented with Structural Health Monitoring System," Int. J. of Structural Stability and Dynamics, vol. 16, issue 4, 1640027, 2016. DOI: $10.1142 / \mathrm{S} 0219455416400277$.

[13] S. Krishnamurthy, R.A. Badcock, V. R. Machavaram, G. F. Fernando "Monitoring pre-stressed composites using optical fibre sensors," Sensors (Switzerland), vol. 16, issue 6, pp. 777, 2016. DOI: 10.3390/s16060777.

[14] S. Fowler, A. Toumpis, A. Galloway, "Fatigue and bending behaviour of friction stir welded DH36 steel," Int. J. Adv. Manuf. Tech, vol. 84, issue 9, pp. 2659-2669, 2016. DOI: 10.1007/s00170-015-7879-3.

[15] V.I. Korotkin, D.A. Gazzaev, "Bending intensity of teeth under the influence of a distributed load in different phases of Novikov gearing," Journal of Machinery Manufacture and Reliability, Volume 43, Issue 2, pp. 104-111, 2014. DOI: 10.3103/S1052618814020083. 